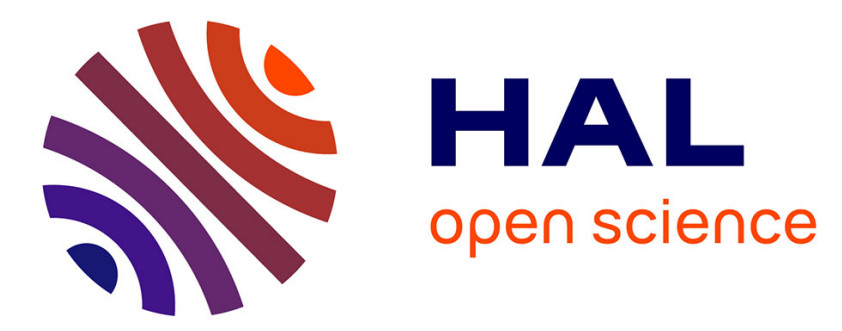

\title{
Emotional distress and subjective impact of the disease in young women with breast cancer and their spouses
}

Christelle Duprez, Laurence Vanlemmens, Aurélie Untas, Pascal Antoine, Anne Lesur, Catherine Loustalot, Cécile Guillemet, Monelle Leclercq, Carine Segura, Damien Carlier, et al.

\section{To cite this version:}

Christelle Duprez, Laurence Vanlemmens, Aurélie Untas, Pascal Antoine, Anne Lesur, et al.. Emotional distress and subjective impact of the disease in young women with breast cancer and their spouses. Future Oncology, 2017, 13 (29), pp.2667-2680. 10.2217/fon-2017-0264 . hal-02457803v2

\section{HAL Id: hal-02457803 \\ https://hal.univ-lille.fr/hal-02457803v2}

Submitted on 17 May 2021

HAL is a multi-disciplinary open access archive for the deposit and dissemination of scientific research documents, whether they are published or not. The documents may come from teaching and research institutions in France or abroad, or from public or private research centers.
L'archive ouverte pluridisciplinaire HAL, est destinée au dépôt et à la diffusion de documents scientifiques de niveau recherche, publiés ou non, émanant des établissements d'enseignement et de recherche français ou étrangers, des laboratoires publics ou privés. 
Emotional distress and subjective impact of the disease in young women with breast cancer and their spouses

Christelle Duprez, Laurence Vanlemmens, Aurélie Untas, Pascal Antoine, Anne Lesur, Catherine Loustalot, Cécile Guillemet, Monelle Leclercq, Carine Segura, Damien Carlier, Claudia Lefeuvre-Plesse, Hélène Simon, Jean Sébastien Frenel \& Véronique Christophe

\section{Abstract}

Aim. Evaluate the influence of emotional distress of young women with breast cancer and their spouses on their daily subjective experience of the disease, through application of the Actor-Partner Interdependence Model.

Patients \& Methods. 112 women aged under 45 years when diagnosed with non-metastatic breast cancer and their spouses answered self-reported measures of anxiety, depression and subjective experience of the disease and its treatment.

Results. The patient's emotional distress influenced more the subjective experience of her spouse than the spouse's emotional distress influenced the patient. The spouse's difficulties depended as much on his own distress level as on the patient's distress level.

Conclusion. These data confirm the importance of implementing couple-focused interventions.

Keywords. Breast cancer, young women, couples, anxiety, depression, subjective experience, interdependence 


\section{INTRODUCTION}

With an estimated 1.7 million cases worldwide and 54062 new cases in France in 2015, breast cancer is the most common cancer in women. It is estimated that one woman in eight will be affected by this cancer during her lifetime [1, 2]. Although novel treatments have significantly improved the survival rate of patients, more than one third of patients experience significant levels of distress [3, 4]. Most of them also exhibit a poorer quality of life, as emotional distress and quality of life are closely associated and evolve over the care pathway and types of treatment (e.g., type of surgery, receipt of adjuvant chemotherapy) [5-7]. Among the women with breast cancer, women diagnosed with non-metastatic breast cancer at a young age ( $<45$ years at diagnosis) have to face problems specific to or accentuated by their young age: a desire for pregnancy sometimes inconsistent with the received treatment, causing fertility related concerns, family roles, difficulties in educating child(ren) who are often very young, marital relationship, changes in body image and its impact on sexuality, or concerns about professional life [8-11]. These stressors contribute to a greater distress and a poorer quality of life, particularly in emotional and social areas, in young women facing breast cancer than in women diagnosed at older ages [12-15]. Concerning their medical treatment, the majority of women under the age of 45 years receive loco-regional treatment (surgery and radiotherapy) and general treatment with chemotherapy, hormone therapy in patients with hormone-sensitive tumor (tamoxifen and / or LH-RH), and immunotherapy with trastuzumab (also called herceptin) for patients with a tumor overexpressing HER2 protein.

Often the main caregiver, the spouse is also greatly impacted by the disease and its treatment in his/her daily life. Their distress levels are also very close to, if not higher than, those of the patients $[16,17]$. Affected by the occurrence of the disease and the effects on their daily life, spouses of women with cancer may feel helpless, not knowing how to support 
their partner [18]. Yet, the spouse's distress and the adjustment strategies he uses to deal with it in turn influence the way the patient adjusts to her disease [19-22]. In recent years, a growing number of studies have highlighted the mutual influential processes between the cancer patient and their spouse in the way each is affected by the disease and deals with its multiple consequences [23-29]. In the context of breast cancer, it has been shown that the patient's distress interacts with her partner's distress [30, 31], and that the emotional distress of one impacts the quality of life of the other [17]. Dorros et al. [32] also demonstrated an interaction effect between stress and depression levels within the dyad: patients' strong depressive affects, associated with a high level of stress whether for herself or her partner, have a deleterious effect on the partner's physical health. Other authors showed that the degree of similarity in the psychological distress in patients and partners influences their respective quality of life [17]. Although it is now well-established that patients and their spouses influence each other in their subjective experience of the disease and in the way they deal with it, to our knowledge no study has focused on the interdependence within the couple regarding the experience of the daily impact of the disease and treatment in young women and their partners.

The present study aims to assess the links between emotional distress (symptoms of anxiety and depression) and the repercussions of the disease and its treatment experienced in daily life in young women diagnosed with non-metastatic breast cancer and their spouses, taking into account the mutual influence within the couple and testing whether dissimilarity in emotional distress affects their respective subjective experience of the disease and treatment.

\section{PATIENTS AND METHODS}




\section{Participants and procedure}

The study was conducted from January 2010 to June 2012 in 27 French centers for cancer treatment. It was proposed to non-metastatic women with breast cancer who had received or were receiving chemotherapy and were aged 18-45 years at the time of their initial diagnosis and to their spouses. The age criterion of 45 or younger was taken from the literature as it applies to young women with breast cancer [33].

Only patients and spouses living as a couple for at least six months at the time of the study, not suffering from psychiatric disorders and fluently French speaking were included in the study. The study was conducted in accordance with regulatory and ethical approvals (Committee of Protection of Persons; Consultative Committee for Data Processing in Research in the Field of Health; National Committee of Data Processing for Data Protection).

The objectives and procedure of the study were explained to the patients during an outpatient appointment. They were told that they and their spouses would each have to answer a questionnaire individually. Conditions of anonymity and confidentiality were guaranteed: the patient's identity did not appear on the study documents (only an anonymous inclusion code made it possible to link the various forms), and the access of the data was restricted to the investigators of the project. Once the woman had signed the consent form, she was given two files (one for herself and one for her partner) containing the questionnaire to complete and a socio-demographic data form, as well as an information letter and a consent form for her spouse. It was the patient's responsibility to suggest that her spouse participate in the study, and no partner could participate without the explicit agreement of the patient. Participants completed the documents at home and then returned the information letter and the consent form to the medical center and the questionnaire to the research unit using the pre-stamped 
envelopes provided for this purpose. At the same time, the patient's medical data were collected by each investigator in the participating centers.

\section{Questionnaires}

Anxiety inventory. The participants were asked to complete the STAI-Y state form [State-Trait Anxiety Inventory [34], French validation by Bruchon-Schweitzer and Paulhan [35], a 20item questionnaire about how they felt "just now, just at the moment" using 4 response alternatives (no / rather not / rather yes / yes). The participants' anxiety level corresponds to the sum of their responses, with possible scores ranging from 20 to 80 . A score higher than 65 indicates a very high level of anxiety, a score ranging from 56 to 65 a high level of anxiety, from 46 to 55 a medium level of anxiety, from 36 to 45 a low level of anxiety, and a score under 35 a very low level of anxiety. Cronbach's alphas in our sample were satisfactory ( $\alpha$ patients $=0.95, \alpha$ partners $=0.96)$.

Depression inventory. Patients and spouses were asked to answer the CESD (Center for Epidemiologic Studies Depression Scale [36], French validation by Fuhrer \& Rouillon [37]), consisting of 20 items about the frequency (never, rarely / occasionally / quite often / often, all the time) at which they had experienced symptoms or behaviors associated with depression during the past week. The total score ranges from 0 to 60 . The higher the score is, the more severe the depressive symptoms are. A score above 17 for men and 23 for women indicates the presence of significant depressive symptoms. The internal consistency of the scale in our sample was good $(\alpha$ patients $=0.82, \alpha$ spouses $=0.84)$.

Subjective experience of the disease and its treatment. Patients were asked to complete the YW-BCI36 (Young Women with Breast Cancer Inventory [38] and partners its corresponding version (Partner YW-BCI36 [39]). This questionnaire was specifically developed and 
validated to identify the problems of young women and their partners and addresses the daily impact of the disease and its treatment. The YW-BCI36 and the Partner YW-BCI36 each contains 36 items and highlights 8 factors: 1) feeling of couple cohesion, 2) negative affectivity and apprehension about the future, 3) management of child(ren) and of everyday life, 4) sharing with close relatives, 5) body image and sexuality, 6) financial difficulties, 7) deterioration of relationships with close relatives, and 8) career management. For each assertion, the participants were instructed to indicate to what extent it corresponded to what they were currently experiencing, from 1 (strongly disagree) to 5 (strongly agree). An average score is calculated for each dimension: the higher the score is, the more the patient/partner has difficulties in the evaluated dimension. The internal consistency of the different dimensions was satisfactory in patients (Cronbach's alphas ranging from 0.73 to 0.86) and spouses (alphas from 0.71 to 0.88 ), except for body image and career management for which internal consistency was a bit low for spouses $(\alpha=0.68)$.

\section{Statistical analyses}

The levels of emotional distress and the difficulties in the different dimensions of the subjective experience of the disease and treatment were first compared between patients and spouses using paired t-tests. The interdependence between the two members of the dyad on the different variables was also assessed using correlations (Pearson two-tailed zero order correlations).

The main question of this study (i.e., investigating the mutual influence within the couple in terms of the impact of anxiety symptoms and depression symptoms on the subjective experience of the disease and treatment) was tested using the Actor-Partner Interdependence Model (APIM [40]). This model differentiates two types of effect within a dyad: an actor effect (i.e., the extent to which a person's score on a predictor variable affects his/her own 
score on an outcome variable; e.g., how does the patient's symptoms of anxiety affect her difficulties in managing her child(ren) and everyday life?), and a partner effect (i.e., the extent to which a person's score on a predictor variable affects the score of the other member of the dyad on an outcome variable, e.g., how does the patient's symptoms of anxiety affect her partner's difficulties in managing his child(ren) and everyday life?). These analyses were conducted using Structural Equation Modeling (SEM) with AMOS ${ }^{\mathrm{TM}}$ version 21 (IBM, NY, USA) software.

According to Kenny et al [40], the purpose of using SEM to test the APIM is to estimate two regression equations with correlated error terms and it is not problematic that the base model is saturated and that no measures of fit can be obtained. Therefore, in this study, the objective is not a model-fit analysis and only parameter estimates are reported. The beta-coefficients from the SEM analyses estimate actor and partner effects: a statistically significant coefficient represents a significant actor or partner effect. Using the APIM, we examined whether the actor effects were equal to the partner effects, comparing the chi-square goodness-of-fit value of the model in which the parameters were forced to be equal to the chi-square goodness-offit value of the original model without constraints. A significant difference indicates that the two effects are not equal $[40,41]$.

The degree to which the patient and her spouse differed in their levels of anxiety and depression was approached by creating “dissimilarity” variables for anxiety level (spouse STAI score - patient STAI score, in absolute value) and depressive mood (spouse CESD score - patient CESD patient score, in absolute value). These variables were entered as predictors in the different models tested. Analyses were carried out separately for anxiety and depression symptoms (predictor variables) and for each of the eight dimensions of the (Partner)YW-BCI36 (outcome variables). The disease duration at the time of the study and 
the patient's current age were controlled in these analyses (Figure 1). To facilitate their reading, the results were reported as figures when two actor effects and at least one partner effect appeared significant.

Insert Figure 1 here

\section{RESULTS}

\section{Participants}

The sample consisted of 112 heterosexual couples living as a couple for 12.70 years on average ( $S D=8.52$, length of the relationship ranging from 1 year to 35), and having at least one child for most of them (86.61\%). At the time of the study, 35.71\% of the patients were being in the follow-up period (after the end of all treatments) 32.14\% were undergoing hormone therapy, 22.32\% chemotherapy and 9.82\% Trastuzumab (Herceptin). The sociodemographic and medical characteristics of the sample are shown in Table 1.

\section{Descriptive analyses}

The majority of patients and spouses showed very low to medium levels of anxiety $(77.67 \%$ of patients, $79.46 \%$ of spouses), but a significant proportion of the sample $(22.31 \%$ of patients, $20.53 \%$ of spouses) reported high to very high anxiety levels, as detailed in Table 1. Similarly, nearly $28 \%$ of patients and $47 \%$ of spouses had significant depressive symptoms.

Insert Table 1 here

Patients were more anxious, had more depressive mood, and overall reported more difficulties in their subjective experience of the disease and treatment than spouses (Table 2). On the other hand, the latter reported more difficulties than patients in sharing with close relatives. 
Patients and spouses exhibited similar difficulties regarding the management of child(ren) and of everyday life, the feeling of couple cohesion, and the deterioration of relationships with close relatives. Except for the sharing with close relatives, negative affectivity and apprehension about the future and career management dimensions, all variables were positively correlated between patients and spouses.

Insert Table 2 here

Anxiety level and subjective experience of the disease and its treatment within the couple

The SEM results showed both actor and partner effects (Table 3). Specifically, except for the sharing with close relatives and career management dimensions, actor effects were found for both patients and partners on every dimension of the subjective experience of the disease and its treatment, always in the sense that the more the patient/spouse felt anxious, the more (s)he experienced difficulties in everyday life (Table 3). Both actor effects could be considered equal, except for the feeling of couple cohesion dimension, for which the actor effect in the patient was stronger than that in the spouse $\left(n=112, d d l=1\right.$, Chi $^{2}$ difference $\left.=3.96, p<.05\right)$.

Regarding the partner effects, the patient's symptoms of anxiety was related to fewer difficulties in sharing with close relatives and to more deterioration of relationships with close relatives in her spouse (Figure 2). The spouse's anxiety symptoms and the patient's anxiety symptoms impacted the spouse's deterioration of relationships with close relatives to the same extent $\left(C h i^{2}\right.$ difference $\left.=0.87, p>.05\right)$. However, the impact of the patient's anxiety symptoms on her own difficulties in sharing with close relatives (actor effect) appeared stronger than its effect on her spouse's difficulties (partner effect, $C h i^{2}$ difference $=15.11, p<$ .001). A partner effect of the spouse on the patient was also revealed: the more anxious the 
man was, the more the woman had difficulties in her career management, the actor effect being equal to the partner effect ( $n=90$ dyads, $C h i^{2}$ difference $=2.37, p>.05$ ), (Table 3).

\author{
Insert Table 3 and Figure 2 here
}

The impact of dissimilarity in anxiety levels on subjective experience revealed no significance.

Depression levels and subjective experience of the disease and treatment within the couple

As expected, actor effects were demonstrated both for the patient and her spouse in every (Partner)YW-BCI36 dimension, except for the sharing with close relatives dimension, for which the spouse's depressive symptoms did not influence his difficulties (Table 3). Both actor effects could be considered equal on most dimensions of subjective experience of the disease and treatment, with the exception of the feeling of couple cohesion $\left(\mathrm{Chi}^{2}\right.$ difference $=$ 5.72, $p<.05)$, and deterioration of relationships with close relatives $\left(C h i^{2}\right.$ difference $=7.96$, $p<.01$ ), for which the actor effect was stronger for patients than spouses.

Interdependence within the couple appeared through the impact of the patient's depressive mood on her spouse's subjective experience (partner effects): the more depressed the patient felt, the more her spouse had difficulties regarding feeling of couple cohesion, finances, and relationships with close relatives (Table 2, Figure 3). For all these dimensions, the influence of the spouse's depression on his own difficulties was comparable to the effect exerted by the patient's depressive mood (difficulties in feeling of couple cohesion: Chi $^{2}$ difference $=0.04, p$ $>.05$; deterioration of relationships with close relatives: Chi $^{2}$ difference $=0.99, p>.05$; financial difficulties: $C h i^{2}$ difference $=0.25, p>.05$ ). 
Insert Figure 3 here

As shown in Figure 3, dissimilarity in depression levels had a significant impact on deterioration of relationships with close relatives in the spouse (the more (dis) similarity, the less the spouse had difficulties in this dimension) and on the sharing with close relatives in the patient (the more (dis) similarity, the more the patient reported difficulties in this dimension).

\section{DISCUSSION}

This study aimed to identify the links between emotional distress and the everyday impact of disease and treatment in young women with breast cancer and their partners, while assessing mutual influence within the couple. While some studies already investigated the mutual influence between patients and their supportive partners whoever they are (spouses, members of the family, friends [32], it seemed crucial to focus on the marital relationship due to the fact the spouse is often the main caregiver - in a dyadic design.

First, our result provide new insights into the difficulties of young couples facing

disease. Young couples facing breast cancer have to deal with concerns either specific or accentuated by their age. For example, some young women may feel less confident in their marital relationships if their relationship is recent due to their young age, and they may still be completing their education or developing their professional career when diagnosed [11]. As a consequence, these life domains may be challenging to manage efficiently while managing the disease (its emotional impact, the medical appointments, the side effects of the treatments). In line with data from the literature, our results showed that young women with breast cancer have high difficulties in body image and sexuality, career management, 
finances, and management of child(ren) and of everyday life. Besides these difficulties in life domains highly invested by young women, the other types of difficulties assessed by the YWBCI, like negative emotions about the future or interpersonal difficulties (difficulties in talking about the disease with close relatives, deterioration of the relationships) may be less specific to young patients and might also appear high in older women with breast cancer, because whatever the age, disease remains a demanding experience.

In agreement with previous findings [3, 4, 42], a significant proportion of patients and partners in our sample also reported significant levels of distress, whether regarding anxiety or depression symptoms. This confirms the vulnerability of this population who is confronted with specific age-related problems. In this study we focused on young couple facing breast cancer, but it is likely that young couples facing other type of cancer would also be vulnerable. The fact that patients and spouses exhibited similar difficulties regarding the management of child(ren) and of everyday life highlights this specific concern faced by young couples and the importance of addressing this difficulty during the care pathway. Furthermore, the spouses reported as many difficulties as the patients concerning the management of child(ren) and of everyday life (i.e., managing the child(ren)'s education, housework), the feeling of couple cohesion (i.e., feeling supported, confiding in one's partner) and the deterioration of relationships with close relatives (i.e., feeling neglected by some close relatives, thinking that the disease created tensions and had a negative impact on relatives). Spouses even reported more difficulties than patients in sharing with relatives. These results not only confirm that the disease has a significant impact on caregivers [42-44], but also suggest that, like the patients [45-48], spouses may have to face social constraints from their relatives. Thinking, rightly or wrongly, that he cannot confide his difficulties in coping with the disease and find support is likely to strengthen further the spouse's distress $[49,50]$. 
Our data especially show that in couples facing cancer, the way each person perceives the daily repercussions of the disease not only depends on his/her own anxiety and depressive symptoms (actor effect) but also on the other person's symptoms (partner effect). While remaining in line with the literature on the mutual influence within the couple [28], our results are innovative to the extent that they relate to young couples and fully identify their specific problems, using two tools specifically created and validated for this purpose [38, 39]. They also show that - with the exception of the partner's anxiety impacting the career management difficulties of the patient (perhaps because of an overprotective attitude that hinders their return to work [51] - it is always the patient's emotional state that influences the daily difficulties of her spouse. Thus, the more anxious the patient is, the less her partner has difficulty in sharing with his relatives (even though his own anxiety has no impact on this type of concern), but the more his relationships with relatives deteriorate. While this may seem counterintuitive at first glance, this result could be related to the emotional charge of the situation, well-known to affect the need to confide in relatives, among others to seek support [52, 53]. Spouses of highly anxious patients could feel the need to talk to their relatives but may not receive effective support or helpful reactions, because of social constraints or confinement in their caregiver role, which means they are not expected to seek support for themselves. We found a consistent pattern of results regarding depressive mood: the more the patient reports being depressed, the more her spouse sees his relationships with relatives deteriorate, as does his feeling of couple cohesion. Interestingly, it also appears that, for most of the evaluated dimensions, the spouse's subjective experience is affected as much by his own emotional distress as by the patient's distress. Although the association between emotional distress and quality of life was already well-established in patients [5, 6], highlighting the impact of emotional distress on different dimensions of the subjective experience of young women with breast cancer and their partners supports the need to assess 
systematically the patient's distress throughout the care pathway [54-57], and to screen the caregiver's distress when possible, which is not yet routine [42, 57].

This need to assess jointly the emotional distress of both members of the couple also appears through the evidence that a "lag" between the patient and her spouse's levels of depression increases the patient's difficulties in talking about the disease with her relatives while limiting the deterioration of relations with close relatives in the spouse. Our data show a different effect of emotional distress on the subjective experience, depending on whether anxiety or depression is considered. In fact, only dissimilarity in depression within couples predicts difficulties, and in a different manner for patients and their spouses. This pattern of results is consistent with the study of Kim et al [17], demonstrating a negative effect of the discrepancy in emotional distress on the mental quality of life of the spouses of patients with prostate cancer Investigating the specific age-related problems in young couples facing disease and examining the couple's "profile” in terms of dissimilarity between the patient's and the spouse's level of distress could help identify the most vulnerable couples in order to offer them tailored supportive care based on their particular difficulties. One possible way to decrease the difficulties of the patients and the partners would be to implement couplefocused interventions focusing on dyadic coping. Especially, in line with the approach developped by Bodenman [58] or Kayser and Scott [59] it would be worth to focus on dyadic coping and communication within these couples facing disease. Interventions would help the patient and her spouse to adopt a «we-ness » approach of the disease and develop mutual coping strategies. Promoting the way to face cancer as a «we-disease », helping the patient and the partner to see the disease as a shared problem that can be faced by joint efforts would promote a better couple adjustement and satisfaction [58-60]. Also, even if we did not assess attachment style in our study, due to the fact at adult age the partner is often the main attachment figure, Emotionnally Focused Therapy could also be implemented: this type of 
therapy would aim to create a secure attachment bond within the couple, helping the patient and her spouse to face disease as well as other life challenges in a more efficient way. This type of therapy has already been assessed with success in chronic disease [61, 62].

To our knowledge, this study is the first to investigate the interdependence in the daily impact of the disease and treatment in young women with breast cancer and their partners. Several limitations should be noted, however, which future studies will alleviate. First, although same-sex couples could be included in the study, only heterosexual couples participated (whether the patients felt, wrongly, it was not appropriate to participate or the investigators did not approach them is not known). It would therefore be interesting to fill this gap by increasing the participation of lesbian couples in future studies, as support and mutual influence processes are potentially different in diseases that may also affect the partner [63, 64]. In addition, although the influence the patient exerts on her partner seems to be stronger than the spouse's influence on the patient, we cannot determine here with certainty whether this effect is related only to the patient/caregiver "roles" or to gender effects $[17,26,65]$. Investigating heterosexual young couples in which the patient is male could also help clarify the interaction between gender roles and the patient/caregiver role. Most importantly, our data were cross-sectional and future studies will benefit from adopting a longitudinal design. For sample size reasons we could not evaluate the impact of the time since diagnosis and type of treatments in the present study. As emotional distress and quality of life evolve over the treatment and care pathway, and even during the survivorship period [7, 66-69], it appears crucial to replicate this study in a longitudinal design investigating the effect of the two factors and the way they can modulate emotional wellbeing and partners and actor effects. Moreover, as emotional distress and quality of life can be affected by marital satisfaction as well as by the quality of communication and perceived support in the couple [20, 47, 70-73], it seems essential to consider these variables in future studies. It would also be interesting to 
investigate further by what processes emotional distress impacts the experience of the disease and treatment, including taking into account emotional regulation/coping strategies implemented by each member of the couple and how they interact, whether individual (e.g., situation appraisal, dedramatization) or dyadic coping strategies (facing cancer as a "we" disease [27, 74-76]). Knowing how the emotional state and quality of life of young patients with breast cancer and their spouses influence each other and evolve over time will help to identify the most difficult moments in the care pathway and then implement the necessary and appropriate interventions.

\section{Conclusions}

To our knowledge, this study is the first to investigate the interdependence in the daily impact of the disease and treatment in young women with breast cancer and their partners, and the data provide clinical applications to explore. First, all these results suggest that couple-focused interventions, taking into account the relationship and the way the spouse is affected by the patient's experience, are particularly appropriate in this population. Considering the couple as a unit rather than the patient or the partner alone may enable the determinants of the daily impact of the disease and treatment to be better targeted, and thus more tailored interventions to be set up in the future [21, 22, 28, 29, 77, 78]. Alleviating the patient's distress would, in turn, reduce the spouse's distress and consequently improve their quality of life. Interventions focused on communication, dyadic coping strategies, or empathy seem particularly relevant [79], as were implemented by Fergus et al [80] as part of an online intervention with young couples facing breast cancer. 


\section{SUMMARY POINTS}

- Young women with non-metastatic breast cancer have to face specific age-related difficulties in their daily life (e.g., parenthood, professional career).

- Their spousal caregivers are also confronted with such difficulties and show high emotional distress.

- Our data show that the patient's emotional distress not only impact the way she faces the daily impact of the disease and its treatments, but also the daily impact of the disease ant its treatments in her partner.

- The spouse's distress also influences the daily difficulties encountered by the patient, demonstrating mutual influence within the couple.

- These results highlight the need to take into account the patients and the spouses distress and respective difficulties due to the disease and its treatment in daily life. Couple-based interventions could promote a better dyadic adjustment to the disease in young couple facing breast cancer. 


\section{Financial and competing interests disclosure}

This paper presents independent research funded by the Ligue Nationale contre le Cancer, the

Conseil Régional du Nord-Pas de Calais, the Prix Ruban Rose 2010, and Sanofi, Roche and Novartis.

The authors declare no conflict of interest. 


\section{Ethical conduct of research}

The study was conducted in accordance with French ethics approvals (Comité de Protection des Personnes) and current French regulations (CCTIRS, CNIL). Consent form was obtained from each participant (patients and spouses) and anonymity and confidentiality were guaranteed for every patient and spouse. 


\section{REFERENCES}

1. Institut National du Cancer. Les cancers en France, édition 2016. Collection Les Données, avril 2017. http://www.e-cancer.fr/Actualites-et-evenements/Actualites/Les-cancersen-France-2016-une-edition-100-interactive (accessed 25.07.17)

2. Peairs KS, Choi Y, Stewart W, \& Sateai HF. Screening for breast cancer. Semin Oncol. 44, 60-72 (2017).

3. Kissane DW, Grabsch B, Love A, Clarke DM, Bloch S, Smith GC. Psychiatric disorder in women with early stage and advanced breast cancer: a comparative analysis. Australian N Z J Psychiatry. 38(5), 320-326 (2004).

4. Zabora J, BrintzenhofeSzoc K, Curbow B, Hooker C, Piantadosi S. The prevalence of psychological distress by cancer site. Psychooncology. 10(1), 19-28 (2001).

5. Ho SSM, So WKW, Leung DYP, Lai ETL, Chan CWH. Anxiety, depression and quality of life in Chinese women with breast cancer during and after treatment: a comparative evaluation. Eur J Oncol Nurs. 17(6), 877-882 (2013).

6. Hutter N, Vogel B, Alexander T, Baumeister H, Helmes A, Bengel J. Are depression and anxiety determinants or indicators of quality of life in breast cancer patients? Psychol Health Med. 18(4), 412-419 (2013).

7. Taira N, Shimozuma K, Shiroiwa $\mathrm{T}$ et al. Associations among baseline variables, treatment-related factors and health-related quality of life 2 years after breast cancer surgery. Breast Cancer Res Treat. 128(3), 735-747 (2011).

8. Anders CK, Johnson R, Litton J, Phillips M, Bleyer A. Breast cancer before age 40 years. Semin Oncol. 36(3), 237-249 (2009).

9. Gabriel CA, Domchek SM. Breast cancer in young women. Breast Cancer Res. 12(5), 212 (2010).

10. Narod SA. Breast cancer in young women. Nature Reviews. Clin Oncol. 9(8), 460-470 
(2012).

11. Greaney ML, Sprunck-Harrild K, Ruddy KJ et al. Study protocol of Young \& Strong: a cluster randomized design to increase attention to unique issues faced by young women with newly diagnosed breast cancer. BMC Public Health. (2015).

12. Mertz BG, Bistrup PE, Johansen C, Dalton SO, Deltour I, Kehlet H, Kroman, N. Psychological distress among women with newly diagnosed breast cancer. Eur $J$ Oncol Nurs. 16(4), 439-443 (2012).

13. Mosher CE, Danoff-Burg S. A review of age differences in psychological adjustment to breast cancer. J Psychosoc Oncol. 23(2-3), 101-114 (2005).

14. Partridge AH, Ruddy KJ, Kennedy J, Winer EP. Model program to improve care for a unique cancer population: young women with breast cancer. J Oncol Pract. 8(5), e105-110 (2012).

15. Phillips KA, Osborne RH, Giles GG, Dite GS, Apicella C, Hopper JL, Milne RL. Psychosocial factors and survival of young women with breast cancer: a populationbased prospective cohort study. J Clin Oncol. 26(28), 4666-4671 (2008).

16. Hasson-Ohayon I, Goldzweig G, Braun M, Galinsky D. Women with advanced breast cancer and their spouses: diversity of support and psychological distress. Psychooncology. 19(11), 1195-1204 (2010).

17. Kim Y, Kashy DA, Wellisch DK, Spillers RL, Kaw CK, Smith TG. Quality of life of couples dealing with cancer: dyadic and individual adjustment among breast and prostate cancer survivors and their spousal caregivers. Ann Behav Med. 35(2), 230-238 (2008).

18. Zahlis EH, Lewis FM. Coming to grips with breast cancer: the spouse's experience with his wife’s first six months. J Psychosoc Oncol. 28(1), 79-97 (2010).

19. Kraemer LM, Stanton AL, Meyerowitz BE, Rowland JH, Ganz PA. A longitudinal 
examination of couples’ coping strategies as predictors of adjustment to breast cancer. J Fam Psychol. 25(6), 963-972 (2011).

20. Manne S, Sherman M, Ross S, Ostroff J, Heyman RE, Fox K. Couples' support-related communication, psychological distress, and relationship satisfaction among women with early stage breast cancer. J Consult Clin Psychol. 72(4), 660-670 (2004).

21. Manne SL, Ostroff J, Winkel G, Grana G, Fox K. Partner unsupportive responses, avoidant coping, and distress among women with early stage breast cancer: patient and partner perspectives. Health Psychol. 24(6), 635-641 (2005).

22. Hubbard G, Menzies S, Flynn P et al. Relational mechanisms and psychological outcomes in couples affected by breast cancer: a systematic narrative analysis of the literature. BMJ Support Palliat Care. 3(3), 309-317 (2013).

23. Lafaye A, Petit S, Richaud P, Houédé N, Baguet F, Cousson-Gélie F. Dyadic effects of coping strategies on emotional state and quality of life in prostate cancer patients and their spouses. Psychooncology. 23(7), 797-803 (2014).

24. Moser MT, Künzler A, Nüssbeck F, Bargetzi M, Znoj HJ. Higher emotional distress in female partners of cancer patients: prevalence and patient-partner interdependencies in a 3-year cohort. Psychooncology. 22(12), 2693-2701 (2013).

25. Segrin C, Badger TA, Harrington J. Interdependent psychological quality of life in dyads adjusting to prostate cancer. Health Psychol. 31(1), 70-79 (2012).

26. Hagedoorn M, Sanderman R, Bolks HN, Tuinstra J, Coyne JC. Distress in couples coping with cancer: a meta-analysis and critical review of role and gender effects. Psychol Bull. 134(1), 1-30 (2008).

27. Kayser K, Watson LE, Andrade JT. Cancer as a « we-disease »: Examining the process of coping from a relational perspective. Fam Syst Health. 25(4), 404-418 (2007).

28. Li Q, Loke AY. A literature review on the mutual impact of the spousal caregiver-cancer 
patients dyads: « communication », « reciprocal influence », and « caregiver-patient congruence ». Eur J Oncol Nurs. 18(1), 58-65 (2014a).

29. Regan TW, Lambert SD, Kelly B, Falconier M, Kissane D, Levesque JV. Couples coping with cancer: exploration of theoretical frameworks from dyadic studies. Psychooncology. (2015).

30. Segrin C, Badger TA. Psychological and physical distress are interdependent in breast cancer survivors and their partners. Psychol Health Med. 19(6), 716-723 (2014).

31. Segrin C, Badger T, Dorros SM, Meek P, Lopez AM. Interdependent anxiety and psychological distress in women with breast cancer and their partners. Psychooncology. 16(7), 634-643 (2007).

32. Dorros SM, Card NA, Segrin C, Badger TA. Interdependence in women with breast cancer and their partners: an interindividual model of distress. J Consult Clin Psychol. 78(1), 121-125 (2010).

33. Dunn J \& Steginga SK. Young women’s experience of breast cancer: Defining young and identifying concerns. Psychooncology. 9, 137-146 (2000).

34. Spielberger CD. State-trait Anxiety Inventory: A comprehensive bibliography. Palo Alto, CA: Consulting Psychologists Press (1983).

35. Bruchon-Schweitzer M, Paulhan I. Manuel pour l'Inventaire d'Anxiété Trait-Etat (Forme Y). Université de Bordeaux 2 (1990).

36. Radloff LS. The CES-D scale: A self report depression scale for research in the general population. Appl Psychol Meas. 1, 385-401 (1977).

37. Fuhrer R, Rouillon F. La version française de l’échelle CES-D (Center for Epidemiologic Studies-Depression Scale). Psychiarie \& Psychobiologie. 4, 163-166 (1989).

38. Christophe V, Duprez C, Congard A, Antoine P, Lesur A, Fournier E, Vanlemmens L. The subjective experience of young women with non-metastatic breast cancer: the 
Young Women with Breast Cancer Inventory. Health Qual Life Outcomes. 13, 73 (2015a).

39. Christophe V, Duprez C, Congard A, Fournier E, Lesur A, Antoine P, Vanlemmens L. Evaluate the subjective experience of the disease and its treatment in the partners of young women with non-metastatic breast cancer. Eur J Cancer Care (2015b).

40. Kenny DA, Kashy DA, Cook WL. Dyadic data analysis. New York, NY: Guilford Press (2006).

41. Cook WL, Kenny DA. The Actor-Partner Interdependence Model: A model of bidirectional effects in developmental studies. Int J Behav Dev. 29(2), 101-109 (2005).

42. Northouse LL, Katapodi MC, Schafenacker AM, Weiss D. The impact of caregiving on the psychological well-being of family caregivers and cancer patients. Semin Oncol Nurs. 28(4), 236-245 (2012).

43. Fletcher BS, Miaskowski C, Given B, Schumacher K. The cancer family caregiving experience: an updated and expanded conceptual model. Eur J Oncol Nurs. 16(4), 387-398 (2012).

44. Hodges LJ, Humphris GM, Macfarlane G. A meta-analytic investigation of the relationship between the psychological distress of cancer patients and their carers. Soc Sci Med.60(1), 1-12 (2005).

45. Donovan-Kicken E, Caughlin JP. Breast cancer patients' topic avoidance and psychological distress: the mediating role of coping. J Health Psychol. 16(4), 596-606 (2011).

46. Milbury K, Badr H, Fossella F, Pisters KM, Carmack CL. Longitudinal associations between caregiver burden and patient and spouse distress in couples coping with lung cancer. Support Care Cancer. 21(9), 2371-2379 (2013).

47. Pasipanodya EC, Parrish BP, Laurenceau JP, Cohen LH, Siegel SD, Graber EC, Belcher 
AJ. Social constraints on disclosure predict daily well-being in couples coping with early-stage breast cancer. J Fam Psychol. 26(4), 661-667 (2012).

48. Adams RN, Winger JG, Mosher CE. A meta-analysis of the relationship between social constraints and distress in cancer patients. J Behav Med. 38(2), 294-305 (2015).

49. Lepore SJ. A social-cognitive processing model of emotional adjustment to cancer. In A.

Baum \& B. L. Andersen (Eds.), Psychosocial interventions for cancer (pp. 99-116). Washington, DC US: American Psychological Association (2001).

50. Lepore SJ, Revenson TA. Social constraints on disclosure and adjustment to cancer. Soc Personal Psychol Compass. 1(1), 313-333 (2007).

51. Johnsson A, Fornander T, Rutqvist LE, Olsson M. Factors influencing return to work: a narrative study of women treated for breast cancer. Eur J Cancer Care. 19(3), 317-323 (2010).

52. Rimé B. Interpersonal Emotion Regulation. In: Handbook of emotion regulation. J. J. Gross (Ed.), New York: Guilford Press, 466-485 (2007).

53. Rimé B. Emotion elicits the social sharing of emotion: Theory and empirical review. Emot Rev. 1, 60-85 (2009).

54. Andersen BL, DeRubeis RJ, Berman BS et al. Screening, assessment, and care of anxiety and depressive symptoms in adults with cancer: An American Society of Clinical Oncology guideline adaptation. J Clin Oncol. 32(15), 1605-1619 (2014).

55. Ryan H, Schofield P, Cockburn J et al. 2005. How to recognize and manage psychological distress in cancer patients. Eur J Cancer Care. 14(1), 7-15 (2005).

56. Vitek L, Rosenzweig MQ, Stollings S. Distress in patients with cancer: definition, assessment, and suggested interventions. Clin J Oncol Nurs. 11(3), 413-418 (2007).

57. Cochrane BB, Lewis FM. Partner's adjustment to breast cancer: a critical analysis of intervention studies. Health Psychol. 24(3), 327-332 (2005). 
58. Bodenman G. Dyadic coping and its significant for marital functioning. In: Revenson, T., Kayser, K., Bodenmann, G. (Eds.), Couples Coping with Stress: Emerging Perspectives on Dyadic Coping. American Psychological Association, Washington, DC, 33-50 (2005).

59. Kayser K and Scott JL. Helping Couples Cope with Women's Cancers. An evidence-based approach for practionners. Springer (2008).

60. Badr H. New frontiers in couple-based interventions in cancer care: refining the prescription for spousal communication. Acta Oncol (2016).

61. Greenman PS, Tassé V, \& Tulloch H. Straight to the Heart: Romantic Relationships, Attachment, and the Management of Cardiac Disease. Rennolds A. Psychology of Perception and Interpersonal Relationships. NY: Nova Science Publishers, 157-174 (2015).

62. Naaman S, Radwan K, \& Johnson S. Coping with Early Breast Cancer: Couple Adjustment Processes and Couple-Based Intervention. Psychiatry. 72(4), 321-345 (2009).

63. Boehmer U, Glickman M, Winter M, Clark MA. Lesbian and bisexual women’s adjustment after a breast cancer diagnosis. J Am Psychiatr Nurses Assoc. 19(5), 280292 (2013).

64. Kamen C, Mustian K, Johnson MO, Boehmer U. Same-sex couples matter in cancer care. J Oncol Pract. 11(2), e212-215 (2015).

65. Li Q, Loke AY. A spectrum of hidden morbidities among spousal caregivers for patients with cancer, and differences between the genders: a review of the literature. Eur $J$ Oncol Nurs. 17(5), 578-587 (2013).

66. Bidstrup PE, Christensen J, Mertz BG, Rottmann N, Dalton SO, Johansen C. Trajectories of distress, anxiety, and depression among women with breast cancer: Looking 
beyond the mean. Acta Oncol. 54(5), 789-796 (2015).

67. Deshields T, Tibbs T, Fan MY, Taylor M. Differences in patterns of depression after treatment for breast cancer. Psychooncology. 15(5), 398-406 (2006).

68. Henselmans I, Helgeson VS, Seltman H, de Vries J, Sanderman R, Ranchor AV. Identification and prediction of distress trajectories in the first year after a breast cancer diagnosis. Health Psychol. 29(2), 160-168 (2010).

69. Montazeri A, Vahdaninia M, Harirchi I, Ebrahimi M, Khaleghi F, Jarvandi S. Quality of life in patients with breast cancer before and after diagnosis: an eighteen months follow-up study. BMC Cancer. 8, 330 (2008).

70. Boeding SE, Pukay-Martin ND, Baucom DH, Porter LS, Kirby JS, Gremore TM, Keefe FJ. Couples and breast cancer: women's mood and partners' marital satisfaction predicting support perception. J Fam Psychol. 28(5), 675-683 (2014).

71. Boinon D, Sultan S, Charles C, Stulz A, Guillemeau C, Delaloge S, Dauchy S. Changes in psychological adjustment over the course of treatment for breast cancer: the predictive role of social sharing and social support. Psychooncology. 23(3), 291-298 (2014).

72. Dagan M, Sanderman R, Hoff C, Meijerink WJHJ, Baas PC, van Haastert M, Hagedoorn M. The interplay between partners' responsiveness and patients' need for emotional expression in couples coping with cancer. J Behav Med. 37(5), 828-838 (2014).

73. Stulz A, Boinon D, Dauchy S, Delaloge S, Brédart A. Psychological adjustment in couples facing woman’s breast cancer: perceptions of spousal support. Bull Cancer. 101(7-8), 690-697 (2014).

74. Badr H, Carmack CL, Kashy DA, Cristofanilli M, Revenson TA. Dyadic coping in metastatic breast cancer. Health Psychol. 29(2), 169-180 (2010).

75. Rottmann N, Hansen DG, Larsen PV, Nicolaisen A, Flyger H, Johansen C, Hagedoorn M. Dyadic coping within couples dealing with breast cancer: A longitudinal, population- 
based study. Health Psychol. 34(5), 486-495 (2015).

76. Traa MJ, De Vries J, Bodenmann G, Oudsten BL. Dyadic coping and relationship functioning in couples coping with cancer: a systematic review. B J Health Psychol. 20(1), 85-114 (2015).

77. Manne S, Badr H. Intimacy and relationship processes in couples' psychosocial adaptation to cancer. Cancer. 112(11 Suppl), 2541-2555 (2008).

78. Badr H, Krebs P. A systematic review and meta-analysis of psychosocial interventions for couples coping with cancer. Psychooncology. 22(8), 1688-1704 (2013).

79. Li Q, Loke AY. A systematic review of spousal couple-based intervention studies for couples coping with cancer: direction for the development of interventions. Psychooncology. 23(7), 731-739 (2014b).

80. Fergus K, Ahmad S, McLeod DL et al. Couplelinks - an online intervention for young women with breast cancer and their male partners: study protocol for a randomized controlled trial. Trials. 16, 33 (2015). 


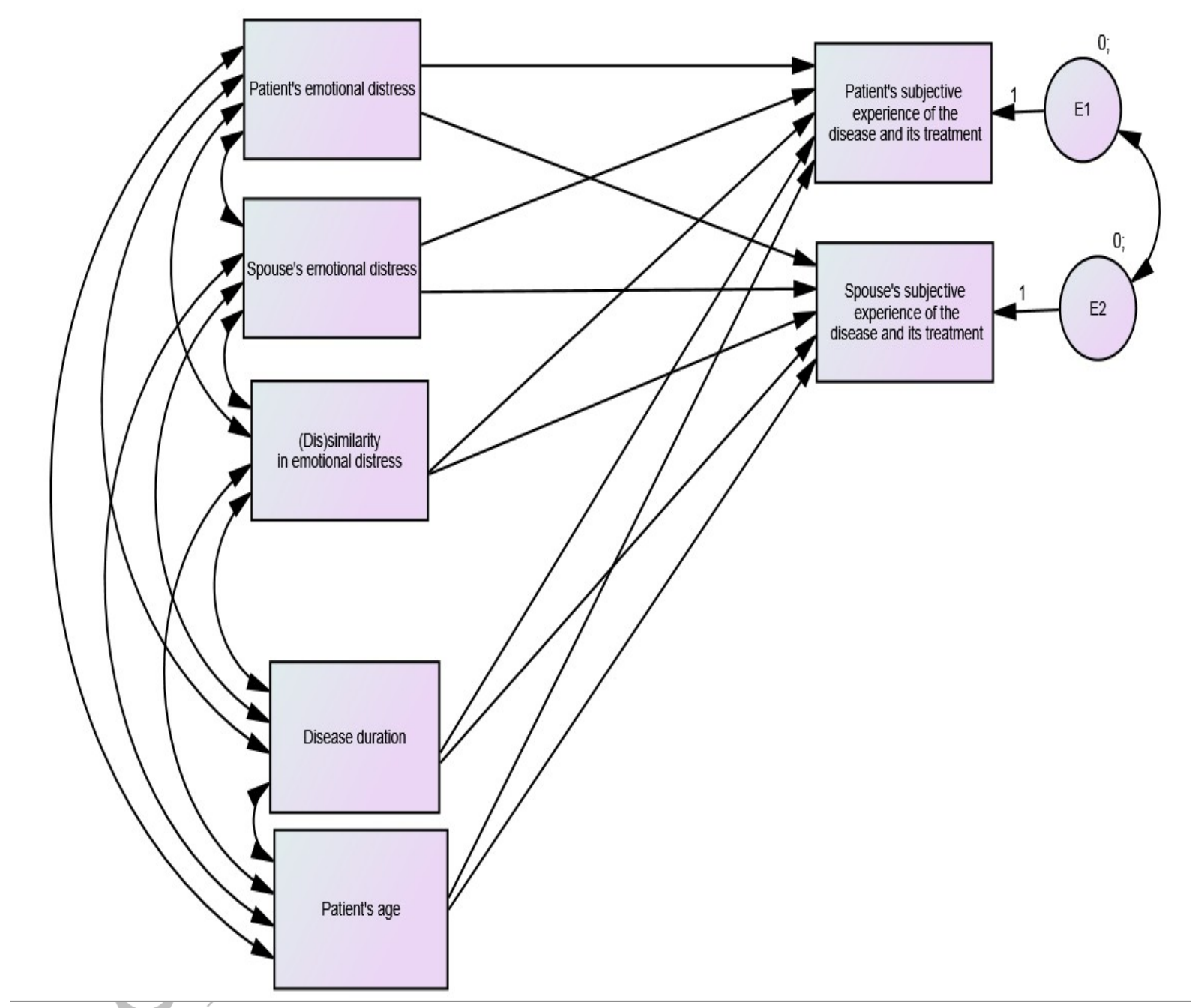

Figure 1. The Actor-Partner Interdependence tested in our study 
Table 1. Characteristics of the respondents

\begin{tabular}{lcc}
\hline & Patients & Spouses \\
\hline Age $(M, S D$, range $)$ & $40.46(6.41)$ & $42.66(7.59)$ \\
& {$[26-56]$} & {$[26-62]$}
\end{tabular}

Length of the relationship (in years: $M, S D$, range)

12.70 (8.52)

[1-35]

Marital status ( $n, \%)$

Married $82(73.21 \%)$

Living as a couple

Presence of child(ren) $(n, \%)$

97 couples (86.61\%)

Education (n, \%)

No certificate

Secondary education diploma - below

Baccalaureate or equivalent diploma

Undergraduate degree

Post graduate degree
$5(4.46 \%)$

$25(22.32 \%)$

22 (19.64\%)

$32(28.57 \%)$

28 (25\%)
$4(3.60 \%)$

$34-(30.63 \%)$

$20(18.02 \%)$

$23(20.72 \%)$

$30(27.03 \%)$

Occupation (n,\%)

Farmers

Craftspeople, shopkeepers, company managers

Executives and intellectual professions Intermediate professions

Employees

Workers

Retired
0

$5(4.50 \%)$

$16(14.41 \%)$

19 (17.12\%)

59 (53.15\%)

5 (4.50\%)

0
2 (1.79\%)

9 (8.04\%)

27 (24.11\%)

24 (21.43\%)

26 (23.21\%)

21 (18.75\%)

$1(0.89 \%)$ 
Unemployed

Years since diagnosis $(M, S D$, range)

First cancer (no recurrence) (n, \%)

Age at diagnosis $(M, S D)$

Medical status at the time of the study (n, \%)

Chemotherapy with or without Trastuzumab

Trastuzumab with or without hormone therapy

Hormone therapy only

Follow-up

Anxiety level (n, \%)
$9(8.03 \%)$

$16(14.28 \%)$

$24(21.43 \%)$

Very low

Depression (n, \%)

Psychotherapy at the time of the study

Anxiolytic/antidepressant treatment at the time of the study

Medium $\quad 37(33.03 \%) \quad 27(24.11 \%)$

Low $26(23.21 \%) \quad 25(22.32 \%)$

$2(1.79 \%)$

2.96 (2.96)

[0.11-11.97]

107 (95.53\%)

37.95 (5.28)

25 (22.32\%)

11 (9.82\%)

$36(32.14 \%)$

$40(35.71 \%)$

37 (33.03\%)

$31(27.68 \%) \quad 52(46.43 \%)$

$10(8.93 \%) \quad 2(1.79 \%)$

$21(18.75 \%) \quad 10(8.93 \%)$ 
Table 2. Descriptive statistics (paired t-test and Pearson correlations)

\begin{tabular}{|c|c|c|c|c|c|c|}
\hline & \multicolumn{2}{|c|}{ Patients } & \multicolumn{2}{|c|}{ Spouses } & \multirow[t]{2}{*}{$t$} & \multirow[t]{2}{*}{$r$} \\
\hline & $M$ & $S D$ & & $S D$ & & \\
\hline Anxiety (STAI score) & 45.65 & 13.59 & 42.09 & 13.70 & $2.34 *$ & $0.30^{* *}$ \\
\hline Depression (CESD score) & 18.49 & 8.09 & 16.73 & 8.16 & $2.02 *$ & $0.36 * * *$ \\
\hline \multicolumn{7}{|l|}{$\begin{array}{l}\text { Difficulties in the subjective experience of the disease } \\
\text { and its treatment ((Partner)YW-BCI36 scores) }\end{array}$} \\
\hline Management of child(ren) and of everyday life & 2.19 & & 2.13 & 0.88 & 0.66 & $0.38 * * *$ \\
\hline Feeling of couple cohesion & 1.85 & 0.76 & 1.78 & 0.63 & 0.92 & $0.34 * * *$ \\
\hline Deterioration of relationships with close relatives & 2.21 & 0.82 & 2.24 & 0.78 & -0.40 & $0.37 * * *$ \\
\hline Sharing with close relatives & 2.08 & 0.86 & 2.55 & 0.83 & $-4.39 * * *$ & 0.09 \\
\hline Negative affectivity and apprehension about the future & $3.46^{\prime}$ & 0.97 & 3.01 & 0.90 & $3.72 * * *$ & 0.08 \\
\hline Body image and sexuality & 3.12 & 1.07 & 2.10 & 0.84 & $9.93^{* * *}$ & $0.37 * * *$ \\
\hline Financial difficulties & 2.75 & 1.06 & 2.48 & 1.006 & $3.06 * *$ & $0.57 * * *$ \\
\hline Career management & 2.73 & 1.07 & 2.28 & 0.89 & $3.38 * *$ & 0.15 \\
\hline
\end{tabular}

Note. ${ }^{*} p<.05,{ }^{* *} p<.01, * * * p<.001$

$\mathrm{N}=112$ couples, except for the career management dimension, for which only 90 dyads were in employment at the time of the study 
Table 3. Standardized coefficients from the SEM analysis testing for actor and partner effects

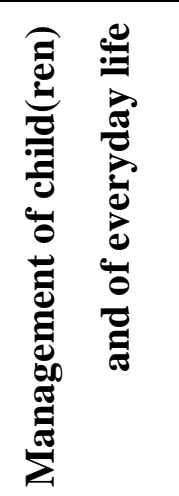

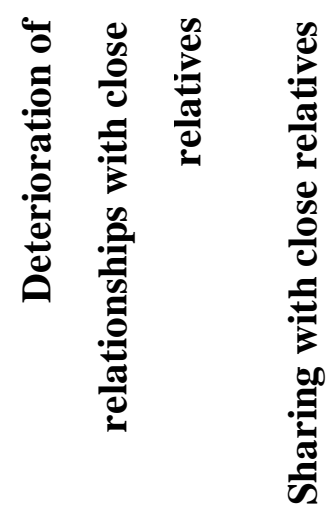
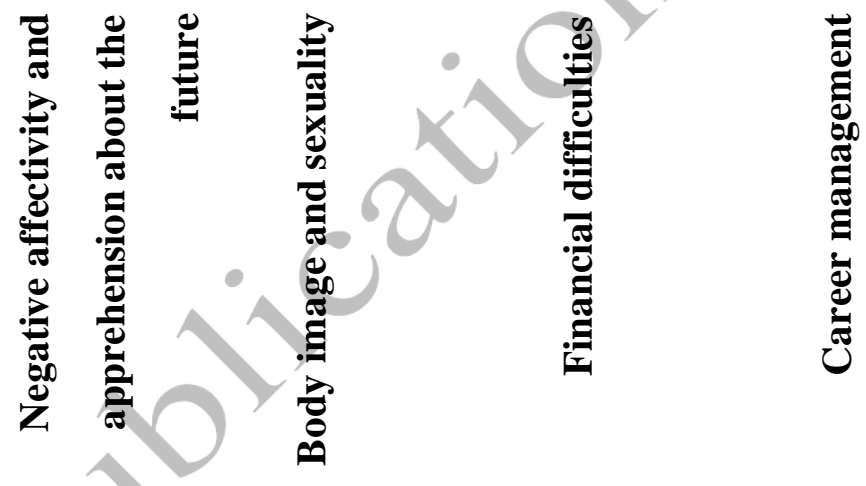

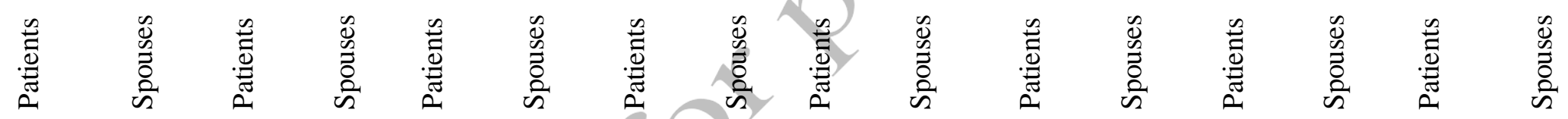

\section{Anxiety}

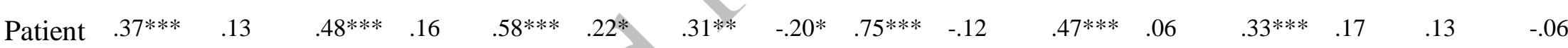

$\begin{array}{llllllllllllllllll}\text { Spouse } & .09 & .45^{* * *} & -.04 & .27^{* *} & .04 & .37 * * * & -.10 & .12 & -.04 & .74^{* * *} & -.04 & .47^{* * *} & .13 & .25^{* *} & .23^{*} & .53^{* * *}\end{array}$

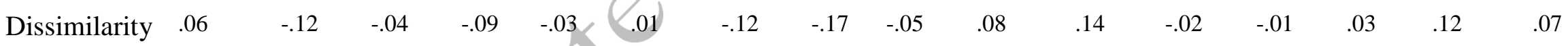

\section{Depression}

$\begin{array}{lllllllllllllllllllllllll}\text { Patient } & .47 * * * & .13 & .48^{* * *} & .24 * & .59 * * * & .39 * * * & .38^{* * *} & -.02 & .57 * * * & -.13 & & .33^{* *} & .06 & .44^{* * *} & .29 * * & .35^{* * *} & -.12\end{array}$ $\begin{array}{llllllllllllllllllllllll}\text { Spouse } & -.01 & .44 * * * & -.12 & .21^{*} & .01 & .25^{* *} & -.18 & .01 & .05 & .62 * * * & -.02 & .34 * * * & .02 & .22 * & .10 & .62 * * *\end{array}$

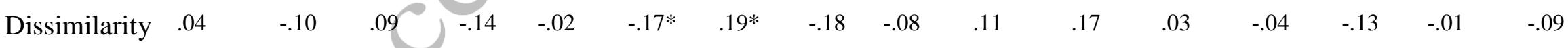

Note. ${ }^{*} p<.05,{ }^{* *} p<.01, * * * p<.001$; disease duration and patient's age were controlled in analyses. 


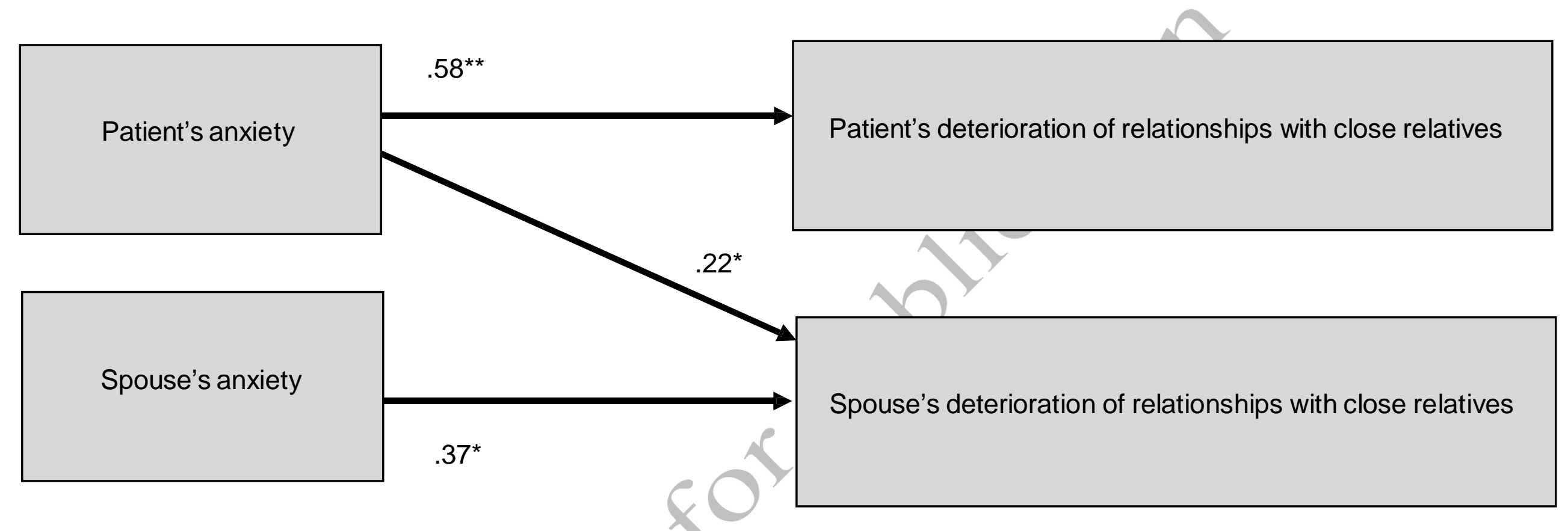

Note. ${ }^{*} p<.01,{ }^{* *} p<.001$

Standardized coefficients are indicated. To facilitate reading, only significant coefficients are shown.

Figure 2. Actor and partner effects of anxiety on deterioration of relationships with close relatives 


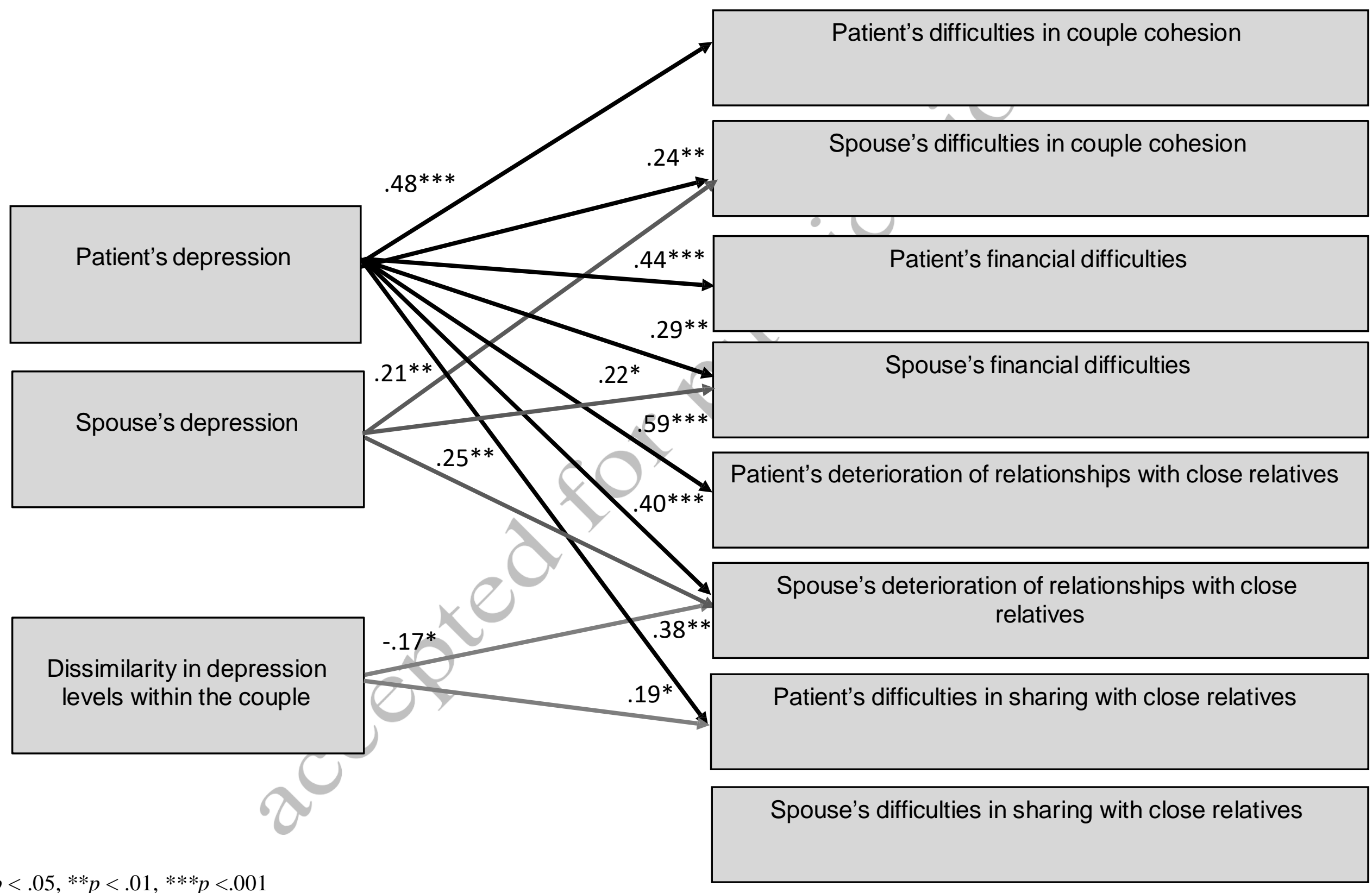

Note. ${ }^{*} p<.05,{ }^{* *} p<.01,{ }^{* * *} p<.001$

Standardized coefficients are indicated. To facilitate reading, only significant coefficients are shown.

Figure 3. Actor and partner effects of depression on subjective experience of the disease and its treatments 